\title{
Recurrent Gastric Carcinoma
}

National Cancer Institute

\section{Source}

National Cancer Institute. Recurrent Gastric Carcinoma. NCI Thesaurus. Code C9237.

The reemergence of gastric carcinoma after a period of remission. 